\title{
A numerical study on cyclic behaviour of polar ice sheets
}

\author{
By J. OERLEMANS, Institute of Meteorology and Oceanography, University of Utrecht, \\ Princetonplein 5, Utrecht, 3508 TA, The Netherlands
}

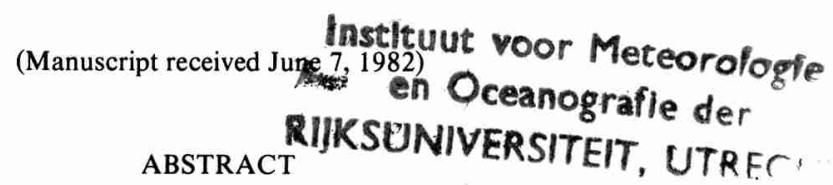

\begin{abstract}
Possible cyclic behaviour of polar ice sheets is studied with a numerical ice-flow model. The model includes a calculation of bedrock adjustment and temperature field in the ice sheet. Basal water is traced and affects ice-mass discharge.

Relaxation oscillations occur only for low ice-accumulation rates (less than $5 \mathrm{~cm}$ ice depth per year). For larger ice-accumulation rates, 2 steady-state regimes exist, depending on temperature: an ice sheet frozen to the bottom, and an ice sheet subject to basal melting everywhere. The volume of the latter is considerably smaller (about $65 \%$ of that of the "cold sheet").
\end{abstract}

In general, the mean basal ice temperature decreases with increasing ice accumulation rate. This is due to the advection term in the heat equation (which has been ignored in earlier studies of ice-sheet surging).

\section{Introduction}

Surging of valley glaciers is a regularly observed feature and its dynamics are reasonably well understood. Ice flow models have been developed (Campbell and Rasmusson, 1969; Budd and McInnes, 1974) that are able to simulate such surges. The basic assumption in these models is the existence of a double-valued relationship between basal shear stress and ice velocity. It results from the fact that locally, the basal stress can be lowered by the production of melt water. If the amount of basal melt water is directly related to the frictional heating, the local reduction of the basal stress can be formulated as

$\frac{\Delta \tau}{\tau}=\frac{1}{1+\phi \tau V}$,

where $\tau$ is the basal stress, $V$ vertical mean ice velocity, and $\phi$ the "lubrication factor". (1) was proposed by Budd and Radok (1971), and subsequently used by Budd and McInnes (1974) (for more details, see Budd, 1975). The term $\phi \tau V$ formulates the "thermodynamics", since it measures the frictional dissipation.

In numerical ice-flow models containing eq. (1), the instability leading to surging is as follows. In the "low ice-velocity mode", $V$ is proportional to some power of the basal shear stress. When $V$ reaches a certain critical value, however, local stress deviations, and consequently longitudinal stress gradients, become so large that $V$ increases substantially (through basal sliding). This leads to a further reduction of $\tau$ and larger ice-mass discharge. Once the slope of the glacier surface has become small, $V$ drops to a low value and the glacier comes in the slow mode again. Gradual build-up then ultimately leads to a new surge.

So whether surge behaviour occurs or not depends on the ice velocity, and therefore essentially on bedrock slope and ice-accumulation rate in the accumulation region of the glacier. It is not surprising that glacier models including a relation of the type of eq. (1) lead to the following classification of glacier systems: (i) slow-mode glaciers, in which frictional heating is too small to create extensive basal sliding; (ii) fast-mode glaciers where extensive basal sliding always occurs: (iii) surging glaciers. These types of behaviour are all observed in nature (Budd, 1975).

Arguments used to explain surging of valley glaciers can also be applied to drainage basins of large continental ice sheets. The idea that parts of the Antarctic Ice Sheet surge quasi-periodically was put forward by Wilson (1964). The subject has 
been discussed by many other workers (e.g. Hollin, 1965, 1972; Hughes, 1973, 1975; Mercer, 1978; Thomas et al., 1979), partly as an ingredient of ice-age theories, partly as events that can be triggered by man-made changes in the environment. To find out whether surging of the Antarctic Ice Sheet is physically plausible, Budd and McInnes (1979) have applied their ice flow model to a flow line of the East Antarctic Ice Sheet. They concluded that large-scale surging is very well possible, and that at a number of locations the ice-mass flux is large enough to maintain a fast or periodic mode.

One serious objection can be made against the application of a glacier model to a large continental ice sheet. Since such an ice sheet is rather thick (typically a few $\mathrm{km}$ ), both downward advection of cold ice and accumulation of geothermal heat are important terms in the energy balance. So it seems that for this case a model in which basal temperature is only controlled (implicitly) by the ice-mass flux is not appropriate. The temperature difference between surface and base of an ice sheet depends strongly on ice thickness and ice accumulation rate (e.g. Paterson, 1969), and therefore these factors should somehow be taken into account. The best way to do this is to include an explicit calculation of the temperature field. Melting or refreezing at the base can then be calculated from a simple energy balance, and flow properties can be directly related to the amount of basal water. Jenssen (1977) developed a model in which the energy equation is solved on a 3-dimensional grid. However, using grid points to calculate the vertical temperature profile requires a lot of computer time, which makes such models inefficient for very long integrations.

In this paper, results are presented from a 2-dimensional ice-flow model in which the energy equation is solved by an approximate method (spectral expansion). Melting or refreezing is calculated explicitly, and the amount of basal water effects the ice-mass discharge. The surge mechanism included in earlier ice-flow models by use of eq. (1) is thus now treated explicitly. Solving the complete energy equation leads to results that differ from those of Budd and McInnes (1979). Without external forcing, periodic behaviour only occurs for low values of the ice-accumulation rate; otherwise, the model ice sheet grows to a steady state with a warm base (the fast mode) or with a cold base (the slow mode), depending on environmental temperature and ice-accumulation rate.

No attempt was made to model a particular flow line of the Antarctic Ice Sheet. The purpose of this paper is to demonstrate that in cyclic behaviour of ice sheets, all terms in the energy equation are important. Very "clean" experiments were carried out, with simple bedrock profile, fixed ice-sheet edge, and constant ice-accumulation rate. These experiments show that the approach works well, and that it seems worthwhile to include the present procedure of calculating temperature-ice flow interaction in a 3-dimensional model of the Antarctic Ice Sheet.

\section{Model description}

The geometry of the model is shown in Fig. 1. One half of a continental ice sheet is considered. The origin of the $x$-axis is at the ice divide, where all horizontal derivatives of state variables are zero (boundary condition). The edge of the continent is at $x=1500 \mathrm{~km}$. All computations are carried out on a grid of 31 points, spaced at $50 \mathrm{~km}$. Ice thickness is denoted by $H$, bedrock elevation (with respect to sea level) by $h$, and undisturbed bedrock elevation (no ice load) by $h_{0}$. The ice accumulation rate $G$ is independent of $x$ and time $t$; it will be expressed in ice depth per year.

$$
\frac{\partial H}{\partial t}=-\frac{\partial}{\partial x}(H U)+G
$$

Here $U$ is the vertical mean horizontal ice velocity.

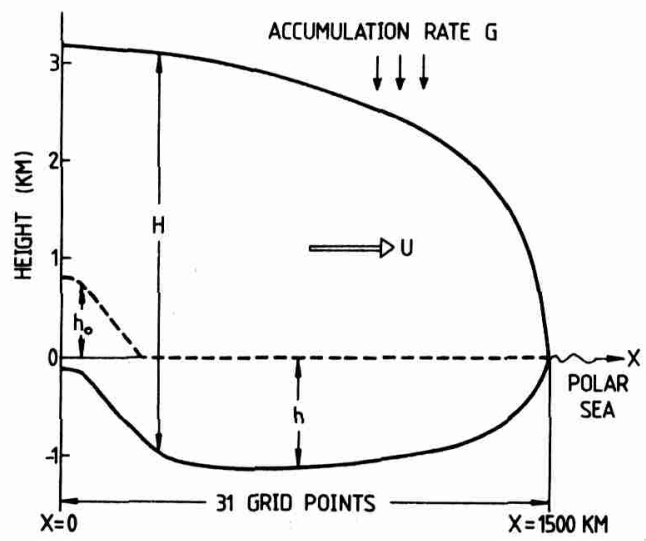

Fig. 1. Geometry of the model ice sheet. 


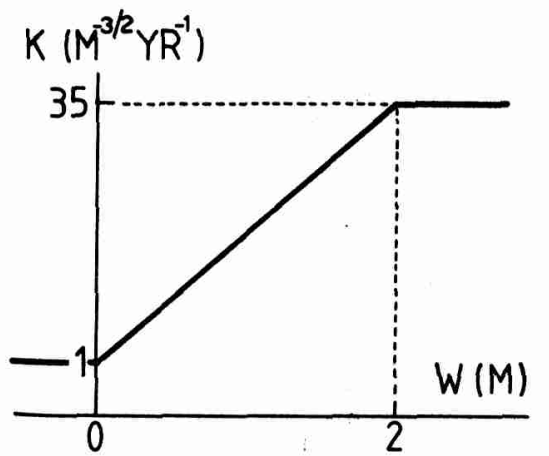

Fig. 2. Effect of basal water $W$ on the flow constant $K$, as parameterized in the model,

It is assumed that $U$ can be related to the basal shear stress $\tau_{b}$ according to a power law (Nye, 1959) $U \doteqdot \tau_{\mathrm{b}}^{m}$. For small surface slope and bedrock slope, and neglecting longitudinal stress gradients, the basal shear stress can be written (e.g. Budd and Radock, 1971)

$\tau_{\mathrm{b}}=\rho g H \frac{\partial}{\partial x}(H+h)$,

where $\rho$ is ice density and $g$ the gravitational acceleration. Absorbing $\rho$ and $g$ in a constant $K$, the following expression for the vertical mean horizontal ice velocity_results:

$U=K\left[H \frac{\partial}{\partial x}(H+h)\right]^{m}$

When $m$ and $K$ are known, eqs. (2) and (4) completely describe the ice flow. In this study, $m$ is set to 2.5 (its value is not crucial). Basic experiments with this model, for constant $K$, were presented in Oerlemans (1981).

Two refinements to this model are now made. First, the reaction of the bedrock to the ice load is computed according to

$$
\frac{\partial h}{\partial t}=-\left(h-h_{0}+q H\right) / T .
$$

Eq. (5) formulates a damped return to isostatic equilibrium with an e-folding time scale $T ; q$ is the ratio of ice density to bedrock density. These constants are set to 4000 years and $q=0.32$, respectively.

Second the flow constant $K$ is made a function of the amount of basal water. According to an analysis by Weertman (1966), the height-to-width ratio of a large continental ice sheet roughly halves when the basal ice is at the melting point everywhere. In the present model, this can be achieved by using a larger value for $K$ when basal water is present. The functional form of $K(W)$, where $W$ is the "grid-square average" amount of basal water, adopted in this study is shown in Fig. 2. It is a simple piecewise linear function of $W$. Changing $K$ from 1 to $35 \mathrm{~m}^{-3 / 2} \mathrm{yr}^{-1}$ in the present ice-flow model leads to a halved ice thickness (all other things being equal).

It should be stressed that this is a very schematic treatment of the effect of basal water on the ice flow. The effect is moderate: typical ice velocities in the case of basal melting are 2 or 3 times as large as velocities in conditions where the ice is frozen to the bottom. Surges produced by the present model are therefore rather slow. The underlying idea is that due to bedrock irregularities, a surge of the valley-glacier type does not occur (except near the ice-sheet edge, in outlet glaciers), but that basal melting leads to a general but moderate increase in ice-mass discharge.

Since the basal temperature is computed explicitly (discussed below), melting or refreezing rates can be easily calculated. The real difficulty lies in the behaviour of the melt water. The flow of basal water is a complicated matter (see Weertman (1972) for a review). Various treatments of melt-water flow have been proposed, but a scheme suitable for the present type of model has yet to be developed. Therefore a simple advection equation is used

$\frac{\partial W}{\partial t}=-a U \frac{\partial W}{\partial x}+M$

Here $M$ is the rate of melting (typical value: a few $\mathrm{mm}$ of ice per year) and $\alpha$ is a fraction ( $\alpha=0.8$ in this study). A diffusive term could also of course be added (some artificial diffusion of melt water is present because the Lax-Wendroff scheme is used to integrate eq. (6)), but this only would introduce another unknown parameter.

Calculation of the temperature field is based on a spectral expansion of the ice temperature $\theta$. 


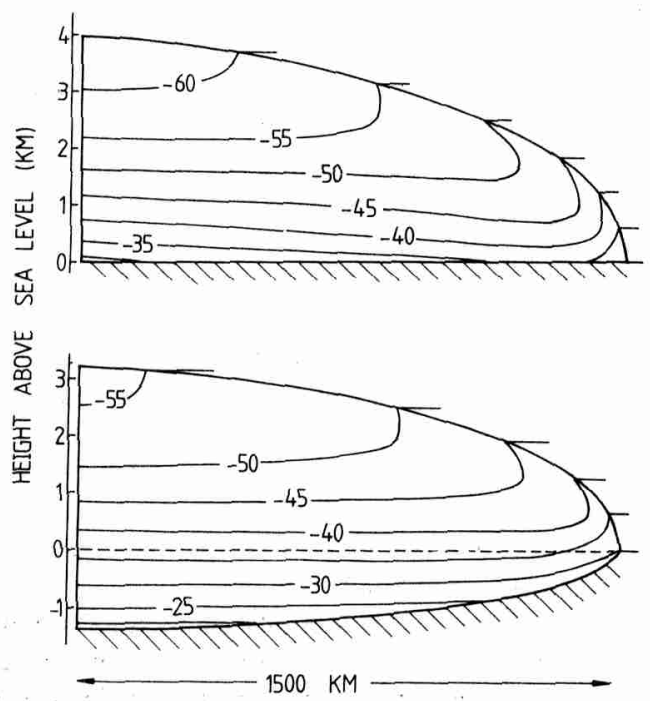

Fig. 3. An example of a calculated steady-state temperature field in a polar ice sheet, with (lower panel) and without (upper panel) bedrock sinking.

Denoting height above the bedrock by $h^{\prime}$, the expansion reads

$$
\begin{aligned}
& \dot{\theta}\left(x, h^{\prime}, t\right) \\
& \quad=\theta_{0}(x, t)+h^{\prime} \theta_{1}(x, t)+h^{\prime 2} \theta_{2}(x, t)+\cdots .
\end{aligned}
$$

Only 3 terms are retained. Equations for $\theta_{0}$ (the basal temperature), $\theta_{1}$ and $\theta_{2}$ can be derived from (i) the upper boundary condition $(\theta(x, H, t)=$ annual atmospheric temperature), (ii) the lower boundary condition $\left(\partial \theta\left(x, h^{\prime}, t\right) /\left.\partial h^{\prime}\right|_{0}\right)$ matches the prescribed geothermal heat flux, and (iii) the vertically integrated heat equation. The method is discussed in detail in Oerlemans (1982). Frictional heating is set equal to the release of potential energy by downward motion, and in order to deal with the advection terms in the heat equation, the velocity profile (scaled by the vertical mean velocity calculated from eq. (3)) is prescribed to be parabolic.

An example of a steady-state temperature distribution is shown in Fig. 3. In this case $G=0.15 \mathrm{~m}$ $\mathrm{yr}^{-1}$ and the temperature lapse rate along the ice surface is $-8 \mathrm{~K} \mathrm{~km}^{-1}$.

Cases with and without adjustment of the bedrock are shown. The annual air temperature at sea level $T_{\mathrm{s}}$ has been set at $-30^{\circ} \mathrm{C}$, in order to prevent basal melting. The calculated temperature fields show 2 characteristic features: the tempera- ture gradient increases with depth, and a tongue of cold ice points toward the ice-sheet edge. Both features are observed in large continental ice sheets (e.g. Paterson, 1980). The highest temperatures are found near the centre of the ice sheet, simply because the ice thickness is largest there.

In this study, interaction between ice temperature and internal deformation is not considered, in order to isolate the effect of basal melting. In future studies in which real ice sheets will be modelled, this interaction will be included. The same applies to such things as grounding line dynamics, variable geothermal heat flux, and timeand space-dependent ice-accumulation rate.

\section{Outline of experiments}

The model is integrated numerically with standard schemes. A variable time step is used, depending on the maximum value of $K(W)$ and $\partial K(W) / \partial x$.

To prevent basal melting starting at $x=0$, which is inconvenient with regard to boundary conditions, a $800 \mathrm{~m}$ ridge in the bedrock is included at the centre of the ice sheet (see Fig. 1). This, by the way, mimics the situation in East Antarctica.

A large number of runs were carried out, all starting with zero initial ice volume. 2 model parameters were varied: the ice accumulation rate and the annual sea-level temperature. All other model constants were fixed to the values already mentioned (the geothermal heat flux was set to 0.04 $\mathrm{W} \mathrm{m} \mathrm{m}^{-2}$ ). It appeared that for some combinations of $G$ and $T_{\mathrm{s}}$, cyclic behaviour occurred. However, before discussing these runs, it is useful to have a look at how steady states depend on the ice accumulation rate.

In Fig. 4, maximum ice thickness, mean basal temperature and maximum basal temperature are shown as a function of ice-accumulation rate. Maximum values of $H$ and $\theta$ are found at the foot of the hill (see Fig. 1). $T_{\mathrm{s}}$ is chosen in such a way that no basal melting occurs. The important result seen from this figure is that basal temperature decreases when the ice-accumulation rate increases, in spite of the fact that a larger ice-accumulation rate is associated with larger ice thickness.

Apparently, the cooling effect associated with stronger downward advection of cold ice over- 


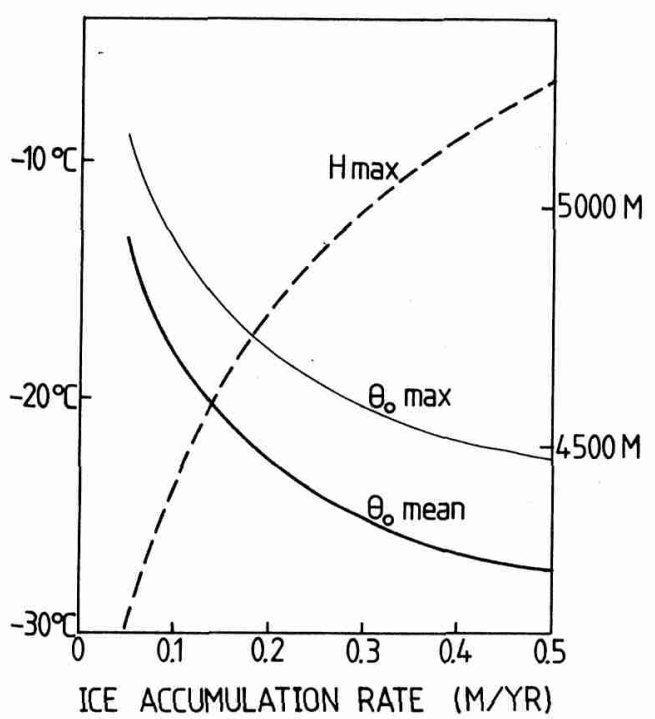

Fig. 4. Dependence of maximum ice thickness, mean and maximum basal temperature on the iceaccumulation rate.

compensates the increased frictional heating and trapping of geothermal heat.

In view of this result, extensive basal melting can be expected in regions where ice thickness is large and accumulation is low.

\section{Results}

Fig. 5 shows a selection of ice-volume curves from the numerical experiments. Numbers within

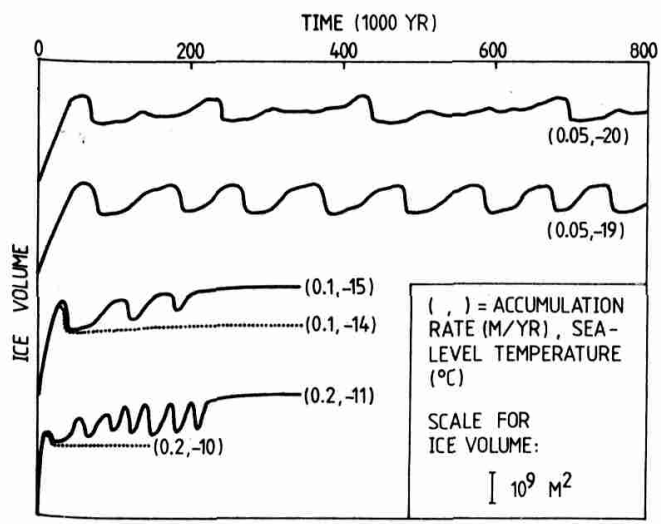

Fig. 5. Ice volume as a function of simulated time for various combinations of $G$ and $T_{\mathrm{s}}$.

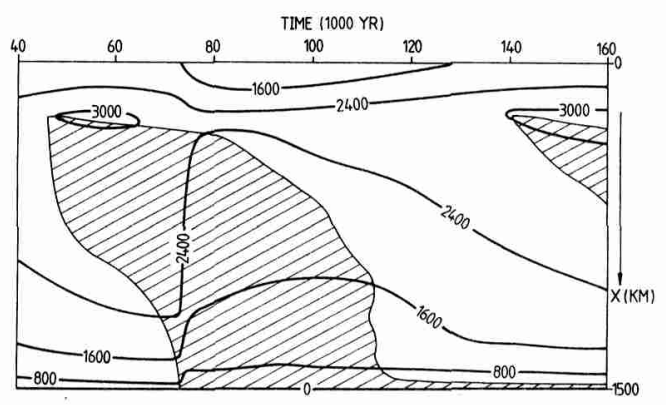

Fig. 6. Close-up of a free oscillation. Ice thickness (solid lines) is given in $m$. Shading indicates the presence of melt water. The picture corresponds to the second curve in Fig. 5.

brackets give the ice-accumulation rate $G$ and the annual sea-level temperature $T_{\mathrm{s}}$.

The second curve shows that cyclic behaviour of the model ice sheet occurs when $G=0.05$ and $T_{s}=$ $-19^{\circ} \mathrm{C}$. Note that there are slight variations in the period of oscillation. For $G=0.05$ and $T_{\mathrm{s}}=$ $-21^{\circ} \mathrm{C}$, the ice sheet grows to a steady state without any basal melting. The transition to a (quasi-) periodic regime occurs somewhere around $T_{\mathrm{s}}=-20^{\circ} \mathrm{C}$. When $T_{\mathrm{s}}$ is higher than about $-17^{\circ} \mathrm{C}$, the cyclic behaviour disappears and a warm-based ice sheet remains.

Fig. 6 provides a close-up of one cycle. It is a running time diagram showing ice thickness and presence of basal water (shaded), corresponding to the second curve in Fig. 5. Due to the low accumulation rate, the mean ice thickness is small and the period of oscillations very long: about 100,000 years. The figure clearly shows how the basal water slowly creeps to the ice-sheet edge. However, this is not purely advection of melt water. Warm ice is also advected to the edge, enhancing the speed at which the edge of the basal water travels, When the basal water reaches the edge, the ice volume decreases rapidly. This takes only a few thousand years. Then frictional heating and trapping of geothermal heat is reduced, and the ice refreezes to the bottom. It is interesting to see that at the edge, the basal water does not disappear. Here the frictional heating is so large that the energy budget remains positive. Consequently, the advection of basal water balances the melting.

Another look at the dynamics of the oscillatory behaviour is given in Fig. 7. It shows trajectories of the model ice sheet in ice volume/ice-mass flux and ice volume/basal water phase planes. Basal water 


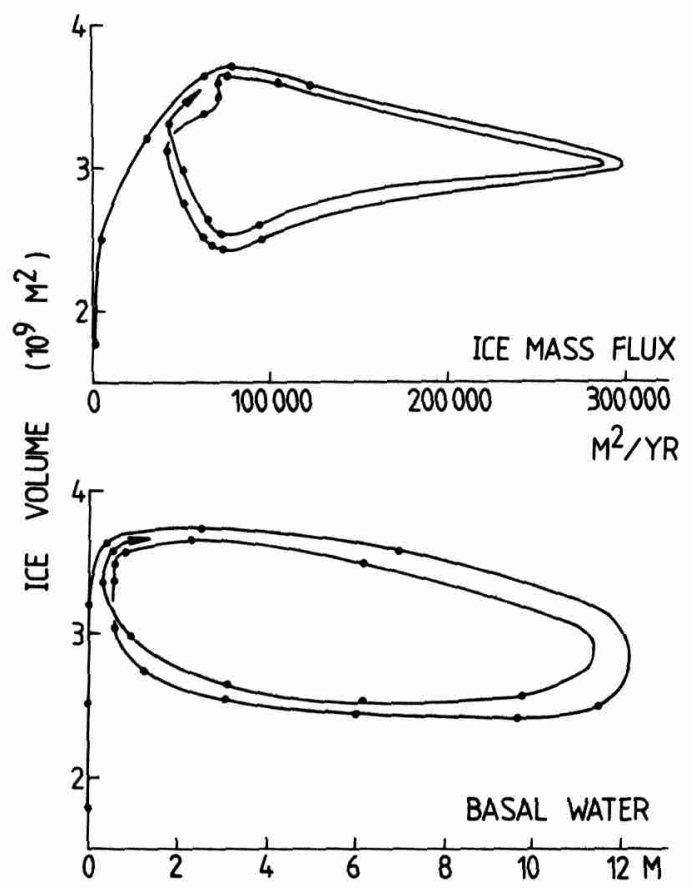

Fig. 7. Trajectories of the model ice sheet in phase planes (for the second curve in Fig. 5).

refers to the mean amount of basal water; the ice-mass flux is the amount of ice entering the ocean. Dots on the trajectories are spaced at 10,000 years. The "relaxation character" of the oscillations can clearly be seen in the upper phase plane.

Returning to Fig. 5, it appears that for $G=0.1$ $\mathrm{m} \mathrm{yr}^{-1}$, free oscillations do not occur any more. For $T_{\mathrm{s}}=-15^{\circ} \mathrm{C}$, a cold-base ice sheet is produced, while for $T_{\mathrm{s}}=-14^{\circ} \mathrm{C}$, basal melt water is always present. Values of $T_{s}$ in between were also tried, but no cyclic behaviour was encountered. The cold base-warm base transition appeared to be at $T_{\mathrm{s}}=$ $-14.8^{\circ} \mathrm{C}$, without any sign of hysteresis (i.e. a warm-base and cold-base steady state for the same value of $T_{\mathrm{s}}$ ). The same type of behaviour occurs for larger accumulation rates.

A detailed exploration of the $G, T_{\mathrm{s}}$-control space finally leads to the classification of ice-sheet behaviour shown in Fig. 8. For low accumulation rate and high temperatures, basal ice is always at the melting point. In contrast, high accumulation rates and low temperatures lead to an ice sheet that is frozen to the bottom everywhere. In between is a

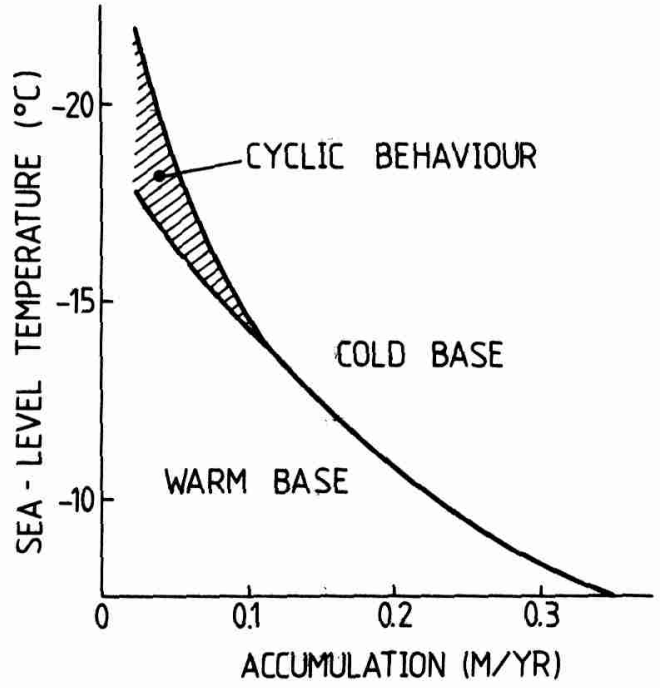

Fig. 8. Dependence of model behaviour on iceaccumulation rate and sea-level temperature.

small wedge, shaded in the figure, where free oscillations occur.

In the vicinity of the cold base-warm base transition, a steady state sometimes occurs in which the thicker part of the ice sheet has basal water, whereas the thinner part is frozen to the bottom. In this case, the production of basal water equals the refreezing near the edge of the "subglacial lake".

\section{Discussion}

Comparing the results of this study with those of Budd and McInnes (1979), an important difference shows up. Budd and MeInnes found that a large ice-mass discharge (corresponding to a large accumulation rate) is a necessary condition for the occurrence of periodic behaviour or a steady state with basal melting. Here the reverse is found: large accumulation rates lead to a cold base. This discrepancy stems from the fact that in the present study, the advection of heat is taken into account. When $G$ increases, the residence time of ice in the ice sheet decreases, and thus the mean ice temperature goes down. So, although neglecting advection of heat may be justified for valley glaciers (which indeed have a warmer base if the ice-mass discharge is larger), it seems to be a wrong assumption when dealing with large ice sheets. 
In this paper only free oscillations are studied. In reality, environmental conditions change continuously and surges may occur simply because the warm base-cold base transition in Fig. 8 is crossed. Since the area where pure free oscillations occur is rather small, it seems that "forced surges" are more likely to occur. One should keep in mind, however, that making $G$ dependent on $x$, or on $H(x)$, may change the picture. In Oerlemans (1982), in which the pleistocene glacial cycles are studied with a similar model, free oscillations appear to have a much larger amplitude when $G$ increases with surface elevation.

The description of ice flow used here does not involve longitudinal stress gradients (in contrast to the work of Budd and collaborators, in which the surge travels along the glacier through longitudinal stress gradients). Once again, the difference in scale must be considered. In the present ice-sheet model, ice velocities during the surge are only twice the ice velocities in the case of a cold base. Consequently longitudinal stress gradients will not be very large.
The idea behind this is that surging of ice sheets is a much slower process than surging of valley glaciers on a smooth bed. When along some flow line in a drainage basin, basal melting and therewith enhanced ice-mass discharge occurs, lateral advection of cold ice will try to damp the initiation of a surge. Also, when large changes in ice thickness occur, it is very questionable whether a flow line can always be identified (as it can be in the case of a valley glacier).

Many more experiments can be carried out with this model, of course. All other model parameters could be varied, and the existence of free oscillations could be investigated for all kinds of functional forms of $G(x, H, t)$. However, this requires a lot of computer time and it seems more worthwhile to spend this on experiments with a 3-dimensional ice-sheet model of Antarctica. The present study has shown in a different approach that large-scale surges of ice sheets are physically plausible. Extension of the model to 3 dimensions seems to be a straightforward matter.

\section{REFERENCES}

Budd, W. F. 1975. A first simple model for periodically self-surging glaciers. J. Glaciol. 14, 3-21.

Budd, W. F. and McInnes, B. J. 1974. Modelling periodically surging glaciers. Science $186,925-927$.

Budd, W. F. and McInnes, B. J. 1979. Periodic surging of the Antarctic ice sheet-an assessment by modelling. Hydrol. Sci. Bull. 24, 95-104.

Budd, W. F. and Radok, U. 1971. Glaciers and other large ice masses, Rep. Prog. Phys. 34, 1-70.

Campbell, W. J. and Rasmussen, L. A. 1969. Threedimensional surges and recoveries in a numerical glacier model. Can. J. Earth Sci. 6, 979-986.

Hollin, J. T. 1965. Wilson's theory of the ice ages. Nature 208, 12-16.

Hollin, J. T. 1972. Interglacial climates and Antarctic ice surges. Quaternary Res. 2, 401-408.

Hughes, T. 1973. Is the West Antarctic ice sheet disintegrating? J. Geophys. Res. 78, 7884-7910.

Hughes, T. 1975. The West Antarctic ice sheet: instability, disintegration and initiation of ice ages. Rev. Geophys. Space Phys. 13, 502-526.

Jenssen, D. 1977. A three-dimensional polar ice-sheet model. J. Glaciol. 18, 373-390.

Mercer, J. H. 1978. West Antarctic Ice Sheet and $\mathrm{CO}_{2}$ greenhouse effect: a threat of disaster. Nature 271, 321-325.

Nye, J. 1959. The motion of ice sheets and glaciers. $J$. Glaciol. 3, 493-507.

Oerlemans, J. 1981. Some basic experiments with a vertically-integrated ice-sheet model. Tellus 33, 1-11.

Oerlemans, J. 1982. Glacial cycle and ice-sheet modelling, Clim. Change, in press.

Paterson, W. S. B. 1969. The physics of glaciers. Oxford: Pergamon Press, 250 pp.

Paterson, W. S. B. 1980 . Ice sheets and ice shelves. In: Dynamics of snow and ice masses (ed. S. C. Colbeck). Academic Press, New York. 468 pp.

Thomas, R. H., Sanderson, T. J. O. and Rose, K. E. 1979. Effect of climatic warming on the West Antarctic Ice Sheet. Nature 277, 355-358.

Weertman, J. 1966. Effect of a basal water layer on the dimensions of ice sheets. J. Glaciol. 6, 191-207.

Weertman, J. 1972. General theory of water flow at the base of a glacier or ice sheet. Rev. Geophys. Space Phys. 10, 287-333.

Wilson, A. T. 1964. Origin of ice ages: an ice shelf theory for Pleistocene glaciation. Nature 201, 147149. 